\title{
Estudio sobre teoría de la mente en personas con síndrome de Down
}

\author{
Study on theory of mind in people with Down syndrome
}

\author{
Iria Pintor García*, Juan Carlos Fernández Méndez* y Antonio Alberto Bello Grela** \\ *Facultad de Ciencias de la Educación, Universidade da Coruña, **Asociación Down Coruña
}

\begin{abstract}
Resumen
La teoría de la mente se puede definir como la capacidad para comprender y predecir la conducta de otras personas, así como sus intenciones y sus creencias. Este trabajo persigue evaluar y entrenar la teoría de la mente en un grupo de doce participantes con síndrome de Down. Los resultados reflejaron que la mayoría de los participantes fracasaron en resolver la tarea mentalista propuesta; por otra parte, cuando se compararon los resultados obtenidos en la evaluación post-entrenamiento tanto del grupo control como del grupo experimental, se puso de manifiesto que el entrenamiento en tareas mentalistas resulta eficaz para superar la tarea de falsa creencia de primer orden.

Palabras clave: evaluación en teoría de la mente, entrenamiento en teoría de la mente, síndrome de Down, prueba de falsa creencias de primer orden y prueba de Sally y Anne.
\end{abstract}

\begin{abstract}
The theory of mind can be defined as the ability to understand and predict the behavior of other people and their intentions and beliefs. This work aims to evaluate and train the theory of mind in a group of twelve participants with Down syndrome. The results showed that most participants failed to resolve the mentalist given task; moreover, when the results of the post- training in both the control group and the experimental group, showed that the training is effective mentalists' tasks to overcome the false belief task of first order evaluation were compared.

Keywords: assessment theory of mind, training in theory of mind, Down syndrome, test first order false beliefs and Sally and Anne test.
\end{abstract}

\section{Introducción}

Los objetivos principales del presente trabajo consisten, por una lado, en evaluar sí un grupo de personas con síndrome de Down (SD) es capaz de predecir la conducta de un individuo que actúa guiado por una creencia errónea y, por otro lado, verificar sí los participantes que fracasen en la resolución de dicha tarea podrán superarla tras el entrenamiento de la teoría de la mente (TdM).

El SD es la discapacidad intelectual de origen genético más frecuente (Hanson, 2004; Kaminker y Armando, 2008). La etiología del síndrome puede explicarse mediante diferentes mecanismos: (a) en el 95\% de los casos se produce una trisomía del cromosoma 21, debido generalmente a la no disyunción meiótica en el óvulo; (b) aproximadamente un $4 \%$ se debe a una translocación entre el cromosoma 21 y otro cromosoma acrocéntrico, que normalmente es el 14 o el 22 y, ocasionalmente, puede encontrarse una translocación entre dos cromosomas 21; (c) por último, un 1\% de los individuos con SD presentan un mosaico, con cariotipo normal y trisomía 21 (Artigas, 2005).

Según Santos y Bajo (2011) el área del lenguaje ha sido descrita como la que presenta un mayor retraso en los niños con SD; sobre todo en los aspectos expresivos, en comparación con los niveles globales del desarrollo, es decir, los niños con SD, aún con un "correcto" desarrollo cognitivo tienen problemas en el lenguaje, siendo los más frecuentes el retraso en la expresión oral y la tartamudez.

Un objeto de estudio cada vez más importante es la cognición social en niños con SD, que puede concebirse como la capacidad de dar sentido a, o captar el sentido de, otras personas (Kunda, 1999, citado por Cebula, Moore y Wishart, 2010). Por su parte, Corrigan, Bental, Racenstein y Newman (1997) la conciben como el conjunto de procesos cognitivos implicados en la manera cómo la gente piensa sobre ella misma, otras personas, situaciones sociales e interacciones (citado por Ruiz-Ruiz, García-Ferrer y Fuentes-Durá, 2006).

Un aspecto relacionado con la cognición social es la “teoría de la mente”, que hace referencia a la "habilidad para comprender y predecir la conducta de otras personas, sus conocimientos, sus intenciones y sus creencias" (Tirapu, Pérez-Sayes, Erekatxo-Bilbao y Pelegrín, 2007, p. 479), mientras que para Uribe, Gómez y Arango (2010) la TdM es un "sistema de conocimientos que permite inferir creencias, deseos, sentimientos $\mathrm{y}$, de esta manera conseguir interpretar, explicar o comprender los comportamientos propios y de otros, así como predecirlos y controlarlos” (p. 28). En ambas definiciones se incorporan elementos relacionados con la comprensión, predicción y control de los comportamientos de uno mismo y de los demás.

Una de las hipótesis más atractivas para explicar la TdM es la que se basa en el sistema de las neuronas espejo (García-García, 2008). Las neuronas espejo son un tipo particular de neuronas que se activan cuando un individuo realiza una acción, pero también cuando se observa una acción similar realizada por otro individuo; de este modo, la simple observación de movimientos de la mano, pie o boca activa las mismas regiones específicas de la corteza motora, como si el observador estuviera realizando esos mismos movimientos.

Como señalan Rodríguez de Guzmán, García, Górriz y Regal (2002) la TdM puede evaluarse mediante una gran variedad de tareas; entre dichas tareas se encuentran las actividades clásicas (denominadas así porque fueron las primeras que se diseñaron para valorar este constructo) 
como las tareas de falsa creencia de primer y segundo orden. Posteriormente, se realizaron ampliaciones mediante actividades como la tarea de las emociones secundarias por transgresión de normas socio-convencionales y morales o las historias extrañas, que permiten conocer la comprensión de la ironía, mentira y mentira piadosa mediante una serie de viñetas cuyos personajes son niños. Dichas tareas se han aplicado a diversos colectivos de personas para evaluar la TdM, tanto con desarrollo típico, como diagnosticados de Trastornos del Espectro Autista o con SD. A diferencia de los estudios llevados a cabo con muestras de personas con desarrollo típico o TEA, que son muy numerosos, no sucede lo mismo con el estudio de la TdM en personas con SD.

Frecuentemente, se han descrito a los niños con SD como personas especialmente amistosas e interesadas en los demás, altamente sociables, con buenas habilidades socio-emocionales y con pocos problemas sociales; bien es cierto que la evidencia pone de manifiesto que existen diferentes perfiles de socialización entre las personas con discapacidad intelectual así como con SD (Izuzquiza, Arribas, Almería, y Ruiz, 2003) y, por tanto, dicha presuposición es un mito. En consecuencia, y en base al mito, se ha dado por sentado que la habilidad de comprensión social está intacta en estas personas; posiblemente por este motivo existen pocos estudios que evalúen las habilidades mentalistas en esta población. Además, los resultados de los primeros estudios, en los cuales se reclutó a niños con SD como grupo control, mostraron que estos niños, al igual que los niños con un desarrollo típico, no experimentaban especiales dificultades en las tareas de TdM (véase, por ejemplo, Baron-Cohen, Leslie y Frith, 1985). Sin embargo, los resultados de estudios posteriores han señalado que, si bien es cierto que los niños con SD no presentan un déficit en la TdM tan marcado como los niños con un Trastorno del Espectro Autista, sí presentan un perfil de dificultades que no se observa en los niños con un desarrollo típico (Amadó, Benejam, Mezuca, Serrat, y Vallès-Majoral, 2012).

En el año 1983, dos psicólogos evolutivos, Wimmer y Perner, idearon una tarea de la falsa creencia. Dicha tarea permitía, sirviéndose del lenguaje, determinar el momento de desarrollo en TdM. La tarea consiste en una historia sencilla, que se va contando al niño o al adulto, al tiempo que se representa mediante muñecas y maquetas. La persona realiza correctamente la tarea cuando es capaz de darse cuenta de que uno de los personajes posee una creencia falsa con respecto a la situación, distinguiéndola de su propia creencia (verdadera) acerca de la localización real del objeto.

Baron-Cohen et al. (1985) aplicaron una forma simplificada de la tarea clásica de Wimmer y Perner a una muestra de niños con autismo, y compararon sus respuestas con las que daban los niños con un desarrollo normal y con SD. Los resultados del estudio demostraron que, a pesar de su mayor edad mental, los niños con autismo tenían un déficit específico en la resolución de la tarea: un 80\% de ellos cometía el "error realista” de decir que la muñeca “objetivamente engañada” buscaría el objeto donde realmente estaba. Parecían incapaces de representarse la creencia falsa del personaje, a diferencia de lo que sucedía con los niños normales de cuatro años y medio de edad mental y cronológica (que daban la respuesta correcta de predicción en un 85\% de los casos), y de los niños con SD, quienes mostraron en general una resolución correcta de la tarea.

En base a la evidencia disponible, en el presente trabajo se evalúa y entrena la teoría de la mente en personas con SD con una prueba de falsa creencia de primer orden, en concreto, la prueba de Sally y Anne de Wimmer y Perner de 1983 (citada por Baron-Cohen, Leslie y Frith, 1985).

\section{Método}

\section{Participantes}

En este estudio colaboraron un total de 24 personas con SD (7 mujeres y 17 varones) con un rango de edad entre 8 y 49 años (media de 23,2 y desviación típica de 8,9). Todos los participantes fueron reclutados de la entidad asociativa Down Coruña, cuya finalidad principal de la asociación es la realización de todas cuantas actividades contribuyan a la mejora de la calidad de vida de las personas con discapacidad intelectual en general, y con síndrome de Down en particular, y la de sus familias, a través de su plena integración social.

Se evaluó la TdM en las 24 personas y, en un segundo momento, fueron seleccionadas 12 personas de las 24 para realizar el entrenamiento. Estas 12 personas (todas ellas varones) debían cumplir los siguientes criterios de selección: (1) diagnóstico confirmado de SD, (2) que hubiesen fracasado previamente en la resolución de la tarea de falsa creencia de primer orden de Sally y Anne (evaluación pre-entrenamiento) y (3) que no tuviesen dificultades que impidiesen el seguimiento de las instrucciones cuando se proporcionasen los apoyos.

Cabe destacar que de este grupo de 12 participantes fue subdividido de manera homogénea, a su vez, en dos subgrupos: un grupo experimental formado por 6 participantes, a los cuales se les evalúa y se entrena en TdM, mientras que el grupo control, formado por otros 6 participantes, solamente son evaluados en TdM (fase pre- y post-entrenamiento).

\section{Instrumentos}

PEABODY PPVT-III. Test vocabulario en imágenes.

Evalúa el nivel de vocabulario receptivo; se trata de una prueba de rendimiento que mide el nivel de adquisición de vocabulario de una persona. Además, puede usarse para la detección rápida de dificultades o como prueba screening de la aptitud verbal. La tercera versión del PEABODY ha sido editada en el año 2010 por Dunn, Dunn y Arribas. El test contiene 192 láminas con cuatro dibujos cada una, en las que el sujeto debe indicar qué ilustración representa mejor el significado de una palabra dada por el examinador, y que se escribirá en la hoja de respuestas.

La prueba permite obtener varias puntuaciones: una puntuación directa, así como la conversión de dicha puntuación en percentiles y eneatipos. Además, se puede obtener un CI y la edad equivalente. 


\section{Prueba de Sally y Anne.}

La tarea mentalista que se ha utilizado para realizar este estudio, tanto para la evaluación pre y post test así como el propio entrenamiento de la TdM, fue la prueba de Sally y Anne. Esta prueba ha sido elaborada en el año 1983 por Wimmer y Perner (citada por Baron-Cohen et al., 1985), y permite evaluar la TdM de los individuos a los que se les aplica.

En el presente trabajo, debido a que los nombres de las niñas están en inglés, se decidió adaptarlos al castellano y en lugar de Sally y Anne, se les llamaron María y Ana, respectivamente, para facilitar el recuerdo de los nombres por parte de los participantes.

Cabe destacar que para la evaluación de la TdM (tanto pre- como post-test) se utilizó dicha prueba representada en viñetas en una hoja de papel. En cuanto al propio entrenamiento, se siguió el mismo guión que la prueba en papel, pero con otros materiales que se explicarán a continuación.

\section{Vídeos.}

En esta investigación se utilizaron dos vídeos para realizar el entrenamiento de la TdM. Estos vídeos fueron elaborados por la primera investigadora de este trabajo. En los vídeos aparecen dos niñas que representan a María y Ana. Las niñas realizan los mismos pasos que se desarrollan en los dibujos en formato de papel. En el vídeo 1 , se puede observar como las niñas interpretan la historia mientras que la investigadora va narrando simultáneamente la historia. Es importante señalar que a lo largo de este vídeo no se ofrece ningún tipo de ayuda. Por su parte, en el vídeo 2, las niñas vuelven a interpretar la misma historia mientras la investigadora la cuenta pero, a diferencia del vídeo 1 , en este caso sí que se ofrecen apoyos, puesto que la niña que interpreta a María va vestida totalmente de color blanco, mientras que la niña que interpreta a Ana va de negro; además, ambas niñas, llevan los nombres de María y Ana escritos en una hoja sobre el pecho. Mediante dichos vídeos se llevaron a cabo los niveles de ayuda 1 (vídeo 1 , sin ayudas visuales) y 2 (vídeo 2, discriminación por color de las prendas de ropa y etiquetación con los nombres de los personajes) del entrenamiento.

\section{Muñecas, cesta, caja y pelota.}

Para realizar este estudio, también se recurrió a dos muñecas (una representaba a María, y la otra a Ana). También se recurrió a una cesta y a un pañuelo para poder cubrirla, así como a una caja con su respectiva tapa y una pelota pequeña. Con estos materiales, lo que se hacía era contar la historia de Sally y Anne a los participantes del grupo experimental con ayuda de las muñecas.

\section{Procedimiento}

La evaluación pre-entrenamiento se llevó a cabo en una de las aulas de la sede de la entidad asociativa Down Coruña. La persona que aplicaba las pruebas era la misma que recogía las respuestas. A cada una de los 24 personas con SD que participaron en la evaluación pre-test, se le administraban en una única sesión el Peabody y, tras una breve pausa, la prueba de Sally y Anne.
Para la administración del Peabody (PPVT-III) se siguieron las instrucciones del propio manual de la prueba. Por su parte, la administración de la tarea mentalista se desarrollaba mediante la presentación de una lámina en la que se encontraba representada gráficamente la historia, y que se acompañaba de la lectura del siguiente texto: “María y Ana están en una habitación; María tiene una cesta y Ana tiene una caja. María coge una pelota y la guarda en su cesta y luego se marcha de la habitación. Entonces queda Ana sola en la habitación y aprovecha que María no la ve para cogerle la pelota de la cesta y meterla en su caja. A continuación llega María. ¿Dónde crees que va a buscar la pelota María? ¿En la cesta o en la caja?”.

El entrenamiento y la evaluación post-entrenamiento se llevó a cabo también en una de las aulas de la sede de la entidad asociativa Down Coruña. Tras la formación de dos grupos homogéneos en cuando a género y edad equivalente proporcionada por el Peabody PPVT-III, el grupo experimental fue sometido a la variable independiente, es decir, a un entrenamiento facilitador de la resolución de la tarea mentalista de falsa creencia de primer orden (prueba de Sally y Anne), mientras que los participantes del grupo control no fueron sometidos a dicho entrenamiento.

El entrenamiento de la TdM fue desarrollado con diferentes niveles de ayuda (concretamente cinco), que requirieron un total de 2 sesiones de 30 minutos de duración con cada participante del grupo experimental, mientras que la evaluación post-entrenamiento solamente se desarrolló en una única sesión de 30 minutos, tanto con el grupo experimental como con el grupo control. Conviene matizar que el período transcurrido entre la fase de entrenamiento y la fase de evaluación post-entrenamiento fue de tres semanas.

Si el participante es capaz de resolver la tarea mentalista en cualquier nivel de ayuda, no se pasa al siguiente nivel de ayuda. Si por el contrario, el participante no es capaz de resolver la tarea en un determinado nivel de ayuda tiene que pasar al siguiente y así sucesivamente.

\section{Resultados}

Los resultados obtenidos a través del Peabody se pueden observar en la Tabla 1.

Tabla 1.

Puntuaciones directas y edades equivalentes obtenidas con el PEABODY

\begin{tabular}{crrr}
\hline & Media (DT) & Mínima & Máxima \\
\hline $\begin{array}{c}\text { Puntuación } \\
\text { directa } \\
\begin{array}{c}\text { Edad } \\
\text { equivalente }\end{array}\end{array}$ & $71.2(26,7)$ & 24 & 148 \\
\hline
\end{tabular}

Cabe destacar que el participante de menos edad cronológica mostraba una puntuación que se encontraba casi al mismo nivel que la del grupo, mientras que el de más edad tenía una puntuación significativamente por debajo de la media del grupo.

En la evaluación pre-entrenamiento (véase Tabla 2), el porcentaje de participantes que acertaron la prueba 
mentalista fue del 37.5\%; además, se encontró una asociación positiva pero no significativa entre la edad cronológica y la resolución de tarea mentalistas $\left(r_{s}=\right.$ 0.195; $p>0.05$ ), así como entre la edad equivalente y la tarea mentalista $\left(r_{s}=0.274 ; p>0.05\right)$.

Tabla 2.

Resultados en la tarea de falsa creencia

\begin{tabular}{llrr}
\hline & Frecuencia & \multicolumn{2}{c}{ Porcentaje } \\
\hline No sabe & & 1 & 4.2 \\
Caja & & 14 & 58.3 \\
Cesta & 9 & 37.5 \\
& Total & 24 & 100.0 \\
\hline
\end{tabular}

Como puede apreciarse en la Tabla 3, cinco de los seis participantes del grupo experimental consiguieron superar la tarea mentalista tras el entrenamiento. Posteriormente, en la evaluación post-entrenamiento, llevada a cabo tres semanas después del entrenamiento, tres de los seis participantes fueron capaces de resolver la tarea de falsa creencia de primer orden que se presentó gráficamente en una hoja de papel. Es importante señalar que las personas que resolvían correctamente la tarea, habían precisado únicamente del nivel 1 de ayuda. Por otro lado, conviene indicar que sólo uno de los participantes del grupo control consiguió resolver la tarea mentalista en la evaluación post-test.

Tabla 3.

Evaluaciones y entrenamiento en la prueba de Sally y Anne

\begin{tabular}{ccccc}
\hline Participantes & $\begin{array}{c}\text { Evaluación } \\
\text { pre-test (1 } \\
\text { evaluación) }\end{array}$ & $\begin{array}{c}\text { Nivel de ayuda } \\
\text { (entrenamiento) }\end{array}$ & $\begin{array}{c}\text { Evaluación } \\
\text { post-test (2 } \\
\text { evaluación) }\end{array}$ \\
\hline 1 & $\mathrm{RI}$ & No resolvió & $\mathrm{RI}$ \\
& 2 & $\mathrm{RI}$ & Ayuda 5 & $\mathrm{RI}$ \\
& 3 & $\mathrm{RI}$ & Ayuda 3 & $\mathrm{RI}$ \\
& 4 & $\mathrm{RI}$ & Ayuda 1 & $\mathrm{RC}$ \\
& 5 & $\mathrm{RI}$ & Ayuda 1 & $\mathrm{RC}$ \\
& 7 & $\mathrm{RI}$ & Ayuda 1 & $\mathrm{RC}$ \\
& 8 & $\mathrm{RI}$ & - & $\mathrm{RI}$ \\
& 9 & $\mathrm{RI}$ & - & $\mathrm{RI}$ \\
& 10 & $\mathrm{RI}$ & - & $\mathrm{RI}$ \\
& 11 & $\mathrm{RI}$ & - & $\mathrm{RC}$ \\
\hline
\end{tabular}

Nota: $R C=$ Respuesta correcta RI = Respuesta incorrecta

\section{Discusión y conclusiones}

Diversos estudios han señalado que la TdM de las personas con SD no está afectada y, por tanto, obtienen resultados similares a los de personas con desarrollo típico, siendo la tarea mentalista de primer orden más utilizada la de Sally y Anne (por ejemplo, Baron-Cohen et al., 1985). Para llevar a cabo su estudio, reclutaron a 20 personas diagnosticadas de autismo, 14 con SD y 27 niños normales igualados en niveles de desarrollo, todos tenían más de 3 años. Mientras que el $80 \%$ de los niños con autismo fracasaban en su intento por dar la respuesta correcta, el 85\% de los niños con desarrollo típico y el $86 \%$ de los niños con SD respondían adecuadamente. Por otra parte, también se sabe que los niños de cuatro años con un desarrollo típico generalmente son capaces de contestar adecuadamente a esta pregunta, diciendo que se encuentra en la cesta. Es decir, son capaces de representarse en su mente el estado de conocimiento de Sally -que no sabe que la pelota no está en su cesta-, porque no han visto el cambio, aun cuando el estado de conocimiento del propio niño sea diferente porque sí sabe dónde está la pelota.

Sin embargo, los resultados obtenidos en este estudio difieren sustancialmente de los encontrados por el equipo de Baron-Cohen (Baron-Cohen et al., 1985): 37,5 versus $86 \%$ de aciertos en la actividad mentalista. Por tanto, en general los participantes de la presente investigación no atribuían ni tenían en cuenta la creencia de Sally (María), aunque recordaban perfectamente dónde metió Sally (María) la pelota y dónde estaba realmente la pelota ahora.

Según Wellman, Cross y Watson (2001), respecto a la población con desarrollo típico, la edad cronológica es una variable que influye en el rendimiento en las tareas de TdM de primer orden; a mayor edad, mejor rendimiento. En lo que se refiere a este estudio, se ha podido comprobar que en los casos de personas con SD, la variable edad cronológica influye a la hora de realizar correctamente o no la tarea mentalista de falsa creencia de primer orden, aunque la relación no fue estadísticamente significativa.

No obstante, una variable importante a tener en cuenta en este estudio es la edad mental o edad equivalente de los participantes. Como advierte Happé (1995), "la edad mental verbal podría estar actuando como una medida de habilidad general, y la estrecha relación que muestra con las tareas de teoría de la mente podría estar mediada por la inteligencia general” (p. 852). En nuestro estudio se aprecia también una asociación positiva entre equivalente (mental) y resolución de la tarea mentalista, pero dicha asociación no resultó significativa.

Por su parte, Monfort y Monfort (2001) también mencionan que las dificultades y expectativas en la resolución de tareas mentalistas en niños con discapacidad intelectual dependen fundamentalmente del nivel de inteligencia y del nivel del lenguaje que estas personas presentan. También apuntan que, en cualquier caso, parece que la experiencia sí tiene un efecto significativo en las personas con discapacidad intelectual, lo que indica que un entrenamiento específico en TdM puede ser útil en estos casos.

Partiendo de los resultados obtenidos en este estudio, se puede observar que, en este caso, hay concordancia con los planteamientos de Happé y con los de Monfort y Monfort, ya que los participantes que lograron resolver la tarea mentalista después de realizar el entrenamiento, eran los que tenían mayores niveles de edad mental equivalente en el Peabody PPVT-III, exceptuando al participante número 6 (quien teniendo una edad mental equivalente de 5 años y 11 meses logró resolver la tarea mentalista con ayuda del entrenamiento).

Los resultados obtenidos en este estudio nos permiten arribar a varias conclusiones. Primera, contrariamente a lo que han mostrado otros estudios (por ejemplo, Baron-Cohen et al., 1985), las personas con SD presentan un desarrollo en TdM inferior a las personas con desarrollo típico. Segunda, el entrenamiento en TdM 
se ha mostrado eficaz en la resolución de la tarea falsa creencia de primer orden. Tercera, en consonancia con la evidencia disponible, se ha encontrado relación positiva entre la edad cronológica y el desarrollo en TdM, es decir, a mayor edad mayor competencia mentalista, o viceversa, aunque dicha asociación no resultó estadísticamente significativa, y también se ha encontrado una asociación entre edad equivalente con el desarrollo en TdM, aunque no resultó significativa.

Conviene indicar que, probablemente, un mayor número de sesiones en el entrenamiento en TdM permitiría alcanzar una eficacia del cien por cien, con esa finalidad se considera muy oportuno que puedan diseñarse futuras líneas de investigación de corte experimental que tengan en cuenta aspectos como el incremento del tamaño de la muestra, procurando establecer diferentes "perfiles" de personas con SD, con edades cronológicas mentales homogéneas, niveles de lenguaje expresivo y comprensivo, etc.; comparar con personas del otro género, en este caso, mujeres, así como con otro grupos de personas: con discapacidad, por ejemplo, TEA, síndromes genéticos, etc., equiparando, en la medida de lo posible, en edad cronológica, mental y verbal; con individuos con desarrollo típico, con diferentes edades cronológicas y edades mentales; realizar el entrenamiento de la TdM con otro tipo de pruebas de falsa creencia de primer orden; y, por último, establecer la comparación en base a pruebas de lenguaje $\mathrm{y}$, especialmente, de valoración de las funciones cognitivas tipo escalas de Wechsler, aplicadas de forma individual.

\section{Referencias bibliográficas}

Amadó, A., Benejan, B., Mezuca, J., Serrat, E. y Vallès-Majoral, E. (2012). Habilidades de cognición social en niños y niñas con el Síndrome de Down: Resultados de un estudio preliminar. Revista Médica Internacional Sobre El Síndrome De Down, 16, 34-39. http://dx.doi.org/10.1016/S1138-2074(12)7002 $6-\mathrm{X}$

Artigas-López, M. (2005). Síndrome de Down (Trisomía 21). Junta Directiva De La Asociación Española De Pediatría, 6, 37-43.

http://www.aeped.es/sites/default/files/documentos/6down.pdf

Baron-Cohen, S., Leslie, A.M. y Frith, U. (1985). Does the autistic child have a theory a theory of mind? Cognition, 21, 37-46. http://dx.doi.org/10.1016/0010-0277(85)90022-8

Cebula, K. R., Moore, D. G. y Wishart, J. G. (2010). La cognición social en los niños con Síndrome de Down. Revista Síndrome De Down, 27, 26-46. http://www.downcantabria.com/revistapdf/104/ 26-46.pdf

Dunn, Ll., Dunn, L. M. y Arribas, D. (2010). PPVT-III. Peabody: Test de vocabulario en imágenes ( $2^{\mathrm{a}}$ ed.). Madrid: Tea.

García-García, E. (2008). Neuropsicología y educación. De las neuronas espejo a la teoría de la mente. Revista De Psicología y Educación, 1,
69-89. http://eprints.ucm.es/9972/1/Revista_Psicologi a_y_Educacion.pdf

Hanson, M. J. (2004). Veinticinco años de intervención temprana. Revista de Síndrome de Down, 21, 42-53. http://www.downcantabria.com/revistapdf/Ate ncion\%20tempranaok.pdf

Happé, F. (1995). The role of age and verbal ability in the theory of mind task performance of subjects with autism. Child Development, 66, 843-855.

http://dx.doi.org/10.2307/1131954

Izuzquiza, D., Arribas, D., Almería, C. y Ruiz, R. (2003). Estudio sobre los perfiles de socialización en las personas con discapacidad intelectual. Madrid: Fundación Prodis.

Kaminker, P. y Armando, R. (2008). Síndrome de Down: Primera parte: Enfoque clínico-genético. Archivos Argentinos De Pediatría, 106, 249-259. http://www.scielo.org.ar/scielo.php?pid=S03 25-00752008000300011\&script=sci_arttext\&tlng=en \#

Monfort, M., y Monfort, I. (2001). En la mente. Un soporte gráfico para el entrenamiento de las habilidades pragmáticas en niños. Madrid: Entha Ediciones. http://www.teccim.es/1/5/Imagenes/enlame nte.pdf

Rodríguez de Guzmán, N., García, E. M., Górriz, A. B. y Regal, R. (2002). ¿Cómo se estudia el desarrollo de la mente? Jornades de Foment de la Investigació de la Universita de Jaume I.

Ruiz-Ruiz, J. C., García-Ferrer, S. y Fuentes-Durá, I. (2006). La relevancia de la cognición social en la esquizofrenia. Apuntes De Psicología, 24, 137-155. http://www.apuntesdepsicologia.es/index.ph p/revista/article/view/74

Santos-Pérez, M. E. y Bajo-Santos, C. (2011). Alteraciones del lenguaje en pacientes afectos de Síndrome de Down. Otorrinolaringológica De Castilla y León, Cantabria y La Rioja, 2, 1-19.

Tirapu-Ustárroz, J., Pérez-Saves, G., Erekatxo-Bilbao, M. y Pelegrín-Valero, C. (2007). ¿Qué es la teoría de la mente? Revista De Neurología, 44, 479-489.

Uribe-Ortiz, D. S., Gómez-Botero, M. y Arango-Tobón, O. E. (2010). Teoría de la mente: Una revisión acerca del desarrollo del concepto. Revista Colombiana De Ciencias Sociales, 1, 28-37. http://funlam.edu.co/revistas/index.php/RCCS/ article/viewFile/1169/1044

Wellman, H. M., Cross, D. R. y Watson, J. (2001). Meta-analysis of theory-of-mind development: the truth about false belief. Child development, 72, 655-684. http://dx.doi.org/10.1111/1467-8624.00304

\section{Agradecimientos}

Agradecemos a la entidad asociativa Down Coruña por hacer posible esta investigación. 